\title{
RENAL, PELVIC AND MESENTERIC TUMORS WITH LOW SIGNAL INTENSITY ON T2-WEIGHTED MR IMAGE: A REVIEW
}

\author{
Dhulaimi Mohammad, ${ }^{1}$ Aldarmasi Moroj ${ }^{2}$ \\ ${ }^{1}$ Radiology Department, King Abdullah Medical Complex, Ministry of Health, Jeddah, Saudi Arabia \\ ${ }^{2}$ Community Medicine Department, Faculty of Medicine, King Abdulaziz University, Jeddah, Saudi Arabia \\ Primljen/Received 19. 08. 2020. god. \\ Prihvaćen/Accepted 13. 11. 2020. god.
}

\begin{abstract}
The magnetic resonance (MR) imaging of intra-abdominal tumors is necessary for clinical practice. MR imaging involves the optimal evaluation of masses due to its inherent soft tissue contrast and multiplanar scanning abilities. T2 low-signal tumors are not common, and individuals need to be careful when interpreting them.

The tumors that contain smooth muscle components, a high nucleus-to-cytoplasm ratio, or papillary architecture, among other components, tend to display low signal intensity on T2-weighted images. MR imaging allows for both the detection and characterization of tumors, especially when they have low signal intensity when presented on T2-weighted images. As a result, it becomes essential to identify the various characteristics that define each tumor.

Identification of the tumor spectrum and knowing the cause of low signal intensity on T2 -weighted images helps the radiologist to narrow the differential diagnosis and reach a final diagnosis.
\end{abstract}

Key words: Magnetic Resonance Imaging, diagnosis, Tumor, Low signal intensity.

\section{INTRODUCTION}

Magnetic resonance (MR) imaging of tumors is necessary for clinical practice. On MR imaging of the abdomen, $\mathrm{T} 1$ and $\mathrm{T} 2$-weighted sequences have always been a key aspect in characterizing tumors. The detection of tumors using T1 and T2-weighted sequences can be affected by various pathological factors. The histological structures tend to impact the $\mathrm{T} 1$ and $\mathrm{T} 2$ duration of relaxation. MR imaging possesses a unique ability in that it explores intracellular content in a way that allows it to recognize substances that can affect signal generation (1).

In most cases, intra-abdominal tumors have a high cellular water mass, which causes them to appear as a high signal intensity (SI) when viewed using T2-weighted imaging. In such a context, radiologists should be well-informed of the various factors that cause low SI as well as the mechanisms through which it occurs on T2-weighted images. They should possess the ability to identify the organ spectrum of tumors that are presented in various imaging findings (1).

\section{MR Imaging and T2 low signal intensity of renal, Pelvic and Mesenteric tumors}

MR imaging involves the optimal evaluation of masses because of its inherent soft tissue contrast and multiplanar abilities. MR imaging aspects of indeterminate masses tend to provide well distinguished morphologic information on tumors such as its location, size, and composition (2). T2-weighted sequences incorporate an integral part of MR imaging that is performed to characterize masses. A greater percentage of intra-abdominal tumors comprise cystic components that display high SI on T2-weighted images. The findings of T2-low signal tumors are not common, which requires care when they are interpreted. These interpretations should be made based on aspects such as pathologic correlates such as smooth muscle, blood products, calcification, high tumor cellularity, and fibrous tissue (2).

Characterizing intra-abdominal tumors requires familiarity with their appearance as well as an analysis of their relationship with the affected or surrounding organs. A wide range of factors cause T2-low signal intra-abdominal tumors. Often, the factors rely on the nature of the tumor as well as the affected organ. Understanding the various causes of intra-abdominal tumors can help in using the correct and most effective method of diagnosis. Some abdominal tumors that are com- 
monly affected by T2 low signal tumors are discussed below (2).

\section{Renal tumors}

Most renal tumors have been described as benign simple and complex epithelial cysts, oncocytomas, metastases, angiomyolipomas, and renal cell carcinomas (RCCs). Sixty-seven percent of renal tumors have also been described as possessing a high possibility of malignancy. Renal tumors can be significantly differentiated using MR images to distinguish between malignant and nonmalignant tumors (3). Necrosis is among the factors that contribute to the generation of low intensity on T2-weighted MR images. While liquefactive necrosis is high on T2-weighted MR, coagulative necrosis is defined by low signal intensity when presented on T2-weighted MR images. The low signal intensity in coagulative necrosis is usually attributed to their dehydration because they do not contain water (4).

Transitional cell carcinomas (TCCs) also contribute to the development of renal tumors. TCCs occur rarely in the upper tract. Usually, TCCs are divided into papillary and non-papillary tumors. TCCs are mostly multifocal and can occur in any part of the collecting system. Although the hematogenous spread is not as common as in RCCs, lymphatic metastases are observed early (5).

The bright signal caused by urine that is present in the collecting system on T2-weighted images offers an excellent soft tissue contrast to facilitate the detection of TCC tumors that are usually seen as having a low SI filling defect (Figure 1) $(6,7)$. Infiltrative TCC can be observed on a single shot of a T2-weighted image as a low signal tissue bulk that subverts the renal parenchyma that possesses an intermediate SI (6). On post-contrast images, infiltrative TCC can be identi-

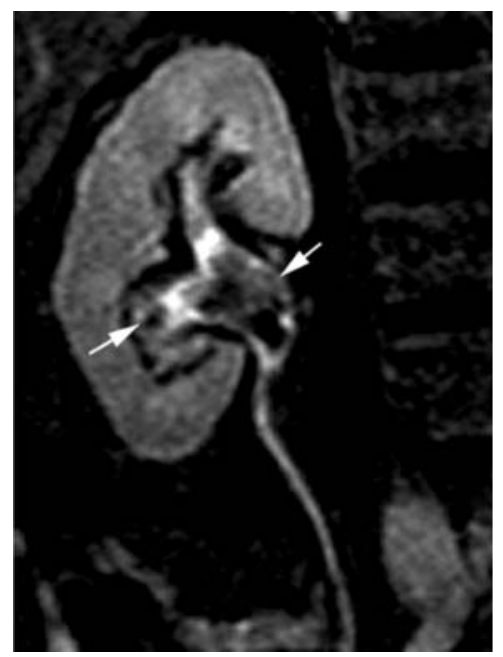

Figure 1. A transitional cell carcinoma as viewed on a low-intensity T2-weighted image (7)

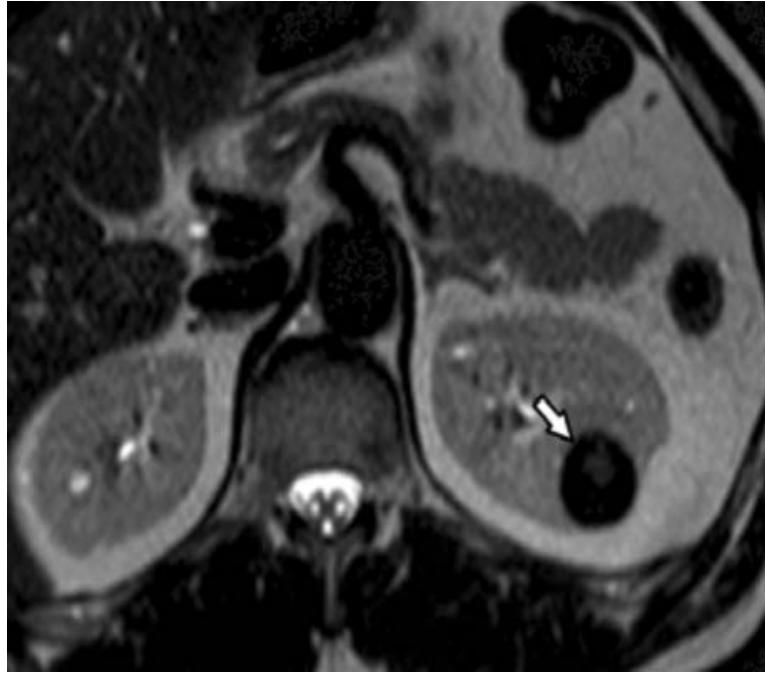

Figure 2. A T2-weighted MR image of low SI papillary renal cell carcinoma (9)

fied as a hypo-enhancing mass, although avid enhancement can take place. MR images produced from the post-contrast acquisition offer a display format that is similar to intravenous pyelograms. In some cases, they can render the findings more conspicuous through contrast with the contralateral kidney.

Papillary RCC (pRCC) forms part of the most commonly occurring RCC types. The tumors present distinctive imaging features that facilitate their differentiation from other types, especially the clear RCC (cRCC). The tumors account for approximately 14 percent of RCC tumors. In most cases, it affects people in the third to eighth decades of life. pRCCs are usually defined by a papillary, tubular, or tubo-papillary pattern of growth $(7,8)$. Compared to clear cell carcinomas, pRCCs have a smaller diameter and are usually at a lower stage of development. pRCCs have histologic characteristics that are closely related to those of papillary adenoma, which is a benign type of renal tumor.

MR images are commonly used to characterize renal tumors. MR imaging is known to provide a tissue contrast that is superior to other imaging techniques. Thus, it is used in imaging pRCCs because it can differentiate solid from cystic tumors. In both $\mathrm{T} 1$ and T2-weighted images, pRCC demonstrates a pseudo-capsule and usually has a low SI (Figure 2) (7). MR images of pRCC show less enhancement compared to cRCC.

Angiomyolipoma (AML) makes one of the most common non-malignant solid renal tumors. A larger percentage of AMLs have a fat content that is easily visible on MR images and CT scans, which makes the tumors diagnosable without surgery or biopsy (10). An estimated five percent of renal AMLs contain little fat that can hardly be identified in MR images. Preoperatively, AMLs with minimal fat are usually difficult to 


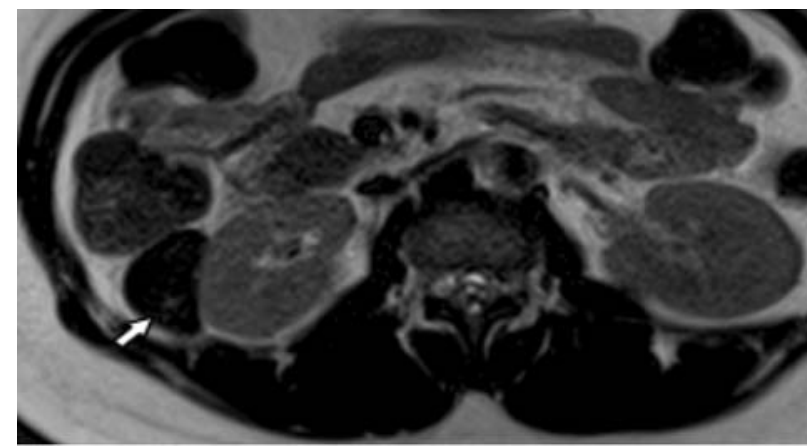

Figure 3. A hypo-intense T2-weighted image showing a fat-poor mass in the renal area (9)

differentiate from RCC when using radiologic examination. Thus, they tend to be diagnosed after surgery (9). On T2-weighted images, AMLs with a high fat content are usually hyper-intense (high signal) contrary to the renal parenchyma. Lipid poor AMLs are T2 hypo-intense (low signal), but they differ in homogeneity depending on the fat distribution (Figure 3 ).

\section{Pelvic Tumors}

The pelvic area is usually prone to tumors that mostly originate from the uterus, fallopian tubes, ovaries, peritoneum, and cervix. MR imaging is used for diagnosis and is usually influenced by the tumor location.

\section{Uterus}

Often, a larger percentage of pelvic tumors are linked to endometrial cancer, which is also the most commonly occurring uterine cancer. On examination, tumors can appear as exophytic masses and in other cases as diffuse endometrial thickening (11). The location of endometrial carcinoma is often based on the extension of the primary tumor. When viewed on T2-weighted images, endometrial cancer tumors have an intermediate low SI (Figure 4) (11). On early contrast-enhanced MR imaging, endometrial carcinoma is enhanced less

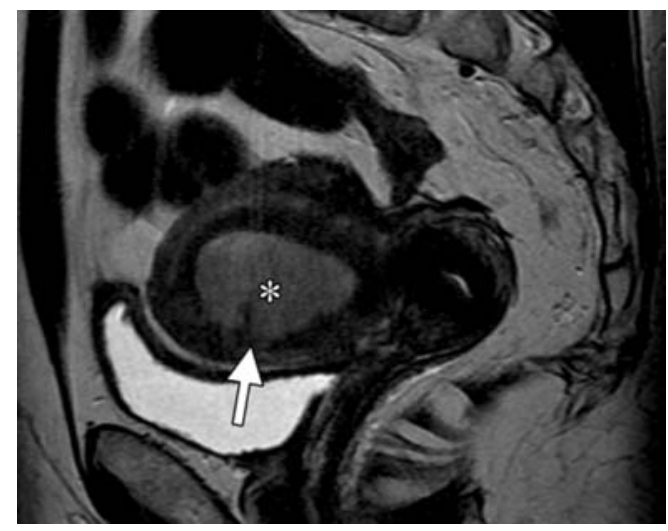

Figure 4. A T2-weighted image of a low signal endometrial cancer (12)

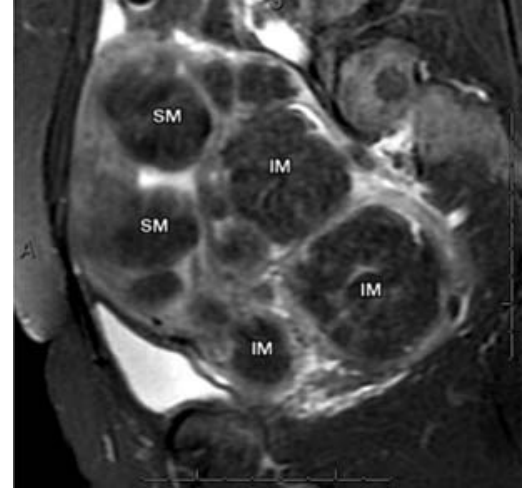

Figure 5. Representation of multiple intramural (IM) and submural (SM) fibroid tumors on a T2-weighted image (13)

than the myometrium on delayed scans, while there is less enhancement differentiation on delayed scans.

Leiomyoma, which is the most common uterine neoplasm, is mostly found in middle-aged women. Leiomyomas contain spindle-shaped cells in a trabecular configuration, creating a whorled appearance. The amount of fibrous tissue, extracellular matrix, and collagen is usually variable (11). The tumors are commonly classified as cervical, intramural, subserosal, and submucosal, depending on where they are located. On T2-weighted images, the tumors appear to be well arranged and have a low SI on T2-weighted images (Figure 5). However, they can have different appearances that depend on the presence of necrosis, cystic degeneration, cellular-type leiomyoma, and hemorrhage.

\section{Ovary}

The ovaries can be affected by a wide range of tumors, which can be malignant or benign, cystic, or solid. Among the variety of tumors that can affect the ovaries are cystadenofibroma, Brenner tumors, and granulosa cell tumors. The ovarian cystadenofibroma is a benign tumor that has both stromal and epithelial constituents (6). It can be malignant on rare occasions,

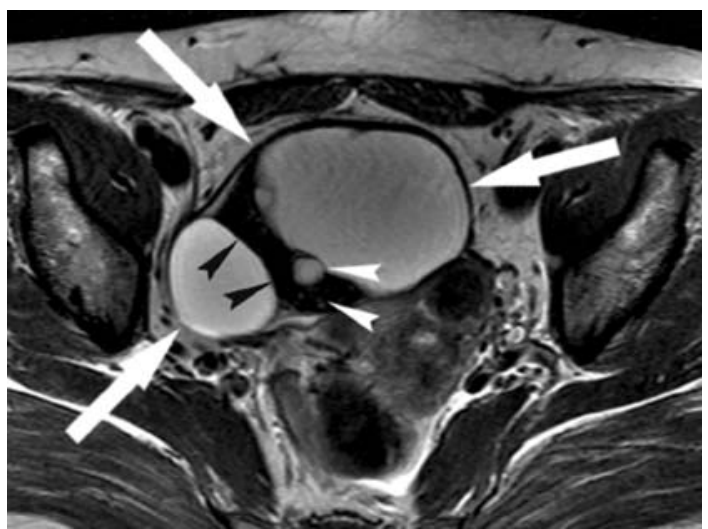

Figure 6. A low-intensity T2-weighted image of a mucinous cystadenofibroma (14) 
but it usually mimics malignancy during imaging because of a well-enhanced solid element that is located in the cystic mass. The solid element displays a low SI that is similar to what is observed in skeletal muscle on T2-weighted MR images because of the fibrous tissue that is present. The characteristic findings of ovarian cystadenofibromas include small cysts that are located within the solid component (6). The diagnosis for cystadenofibroma has a T2 low signal intensity within multilocular cystic masses and large cystic gaps in the glandular elements (Figure 6).

Ovarian fibromas and fibrothecomas form an uncommon group of benign tumors that originate from the stroma. These tumors represent approximately four percent of ovarian neoplasms. Fibromas normally originate from mesenchymal spindle cells that produce collagen, and they can in some cases be linked to Meigs syndrome, which includes ovarian tumors, ascites, and pleural effusion (10). Fibrothecomas originate from spindle cells, but they can contain intracellular lipids. The tumors may also show estrogenic activity. Fibromas and fibrothecomas are normally asymptomatic, and they are usually found incidentally. Often, they occur in post-menopausal and perimenopausal patients in their fifth and sixth decades of life (10). On MR images, the tumors appear with a low SI on T2-weighted images (Figures 7 and 8). Although fibromas and fi-

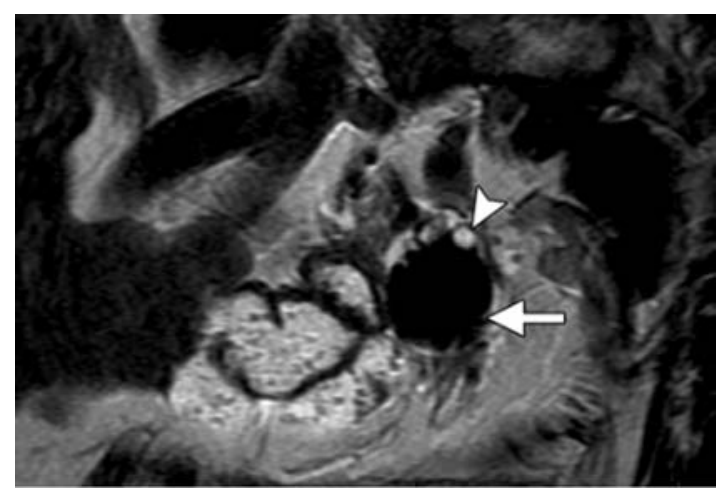

Figure 7. An axial view of a T2-weighted MR image showing a low-intensity mass in the fibroma (15)

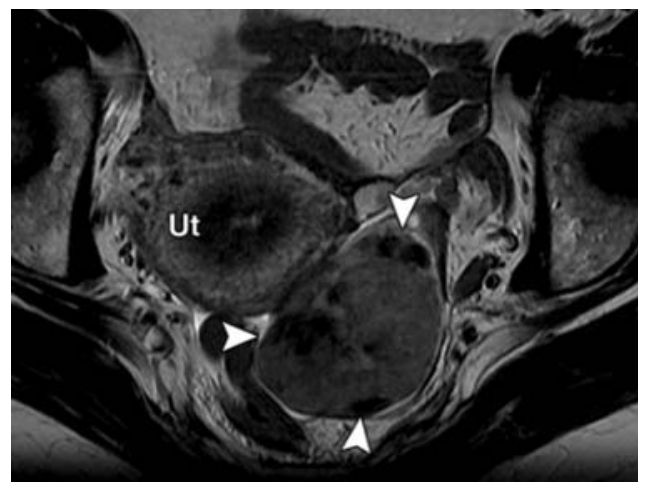

Figure 8. A T2-weighted image of a fibrothecoma showing an intermediate low SI ovarian mass (15)

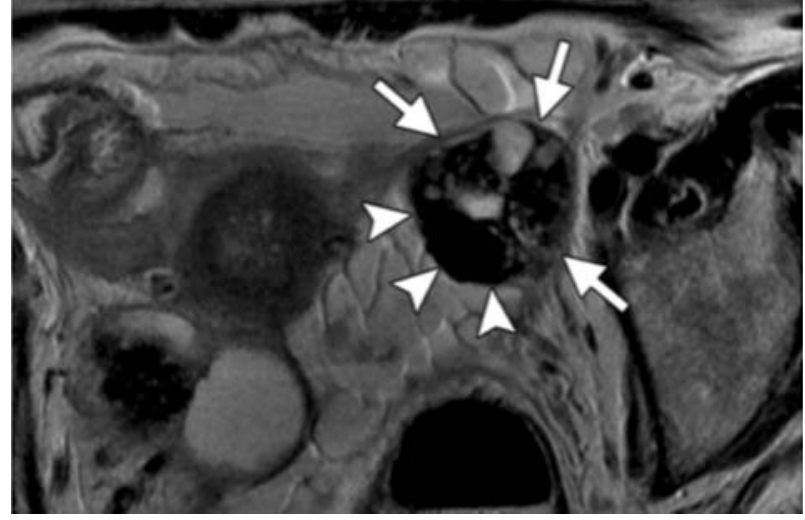

Figure 9. A low-intensity T2-weighted image of a Brenner tumor (15)

brothecomas are often defined as solid masses, they rarely contain cystic components.

Brenner tumors are usually uncommon, and they usually affect women in the fifth decade of life. The tumors are predominantly solid on pathologic and imaging examinations. However, an association with mucinous and serous cystadenomas in approximately 30 percent of patients may show a cystic appearance when the tumor is very small or visually inseparable from the coexisting cystic neoplasm (9). On pathologic examination, Brenner tumors can range from 0.3 to $12 \mathrm{~cm}$ and contain epithelial nests that are surrounded by proliferating dense stromal tissue. MR imaging shows T2-weighted hypo-intense (low SI) solid elements that have fibrous tissue that is similar to fibromas (Figure 9).

Clear cell adenocarcinomas form between five and ten percent of ovarian tumors. Often, nulliparity is associated with endometriosis as well as endometrioid cysts. The symptoms of the tumor can range from abdominal discomfort, distention, and pain to gastrointestinal symptoms. Gross examination of the tumor shows that it appears to contain solid and cystic constituents (16). A larger percentage of the tumors are usually unilocular cystic masses. The solid components of the cyst are usually hypo-intense (low signal) on T2-weighted MR images. In cystic tumors, gadolinium-based contrast of solid components is displayed as being helpful during the diagnosis process (16). Peritoneal and ascites enhancement is essential for predicting the tumor malignancy.

\section{Prostate}

Prostate cancer causes approximately ten percent of cancer-related deaths. An examination of prostate carcinoma shows a recognizable pattern of glands. In other cases, it can display nests, cords, or sheets of cells. T2-weighted images tend to define anatomic aspects of the tumor and present a clear distinction between peripheral and transition locations. The typical 


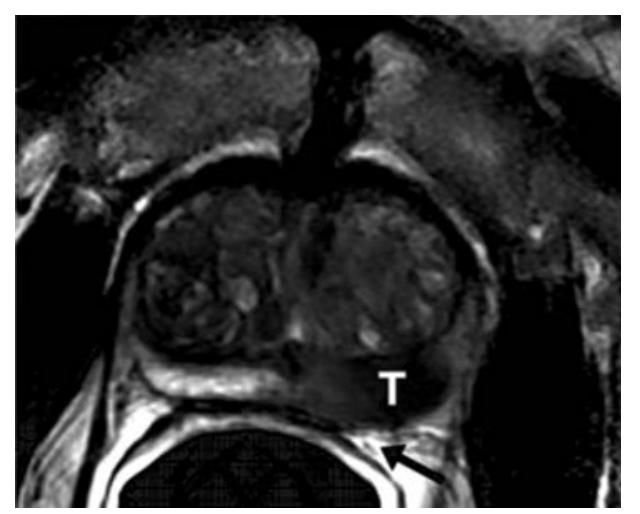

Figure 10. A low-intensity T2-weighted image of the prostate carcinoma (17)

prostate carcinoma displays a focal low SI on T2-weighted images (Figure 10). The diagnosis for prostate carcinoma includes two-dimensional electrophoresis and a positive prostate biopsy (1).

\section{Mesenteric and bowel tumors}

Mesenteric tumors form part of the most common hypo-intense (low signal) tumors on T2-weighted images. Depending on where they are located, leiomyomas

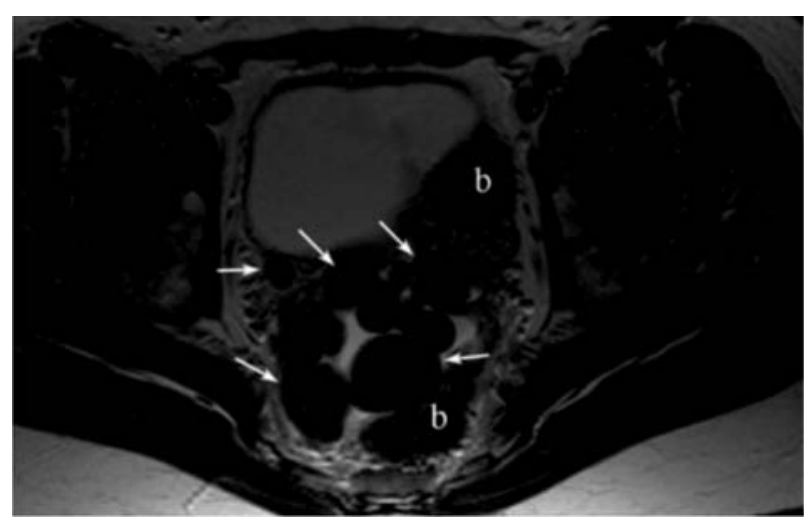

Figure 11. A low-intensity T2-weighted image of a peritoneal leiomyomas (19)

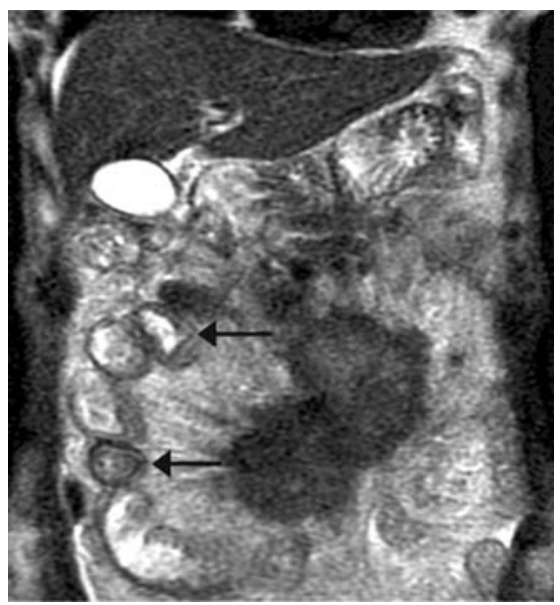

Figure 12. A T2-weighted image of a carcinoid tumors (14)

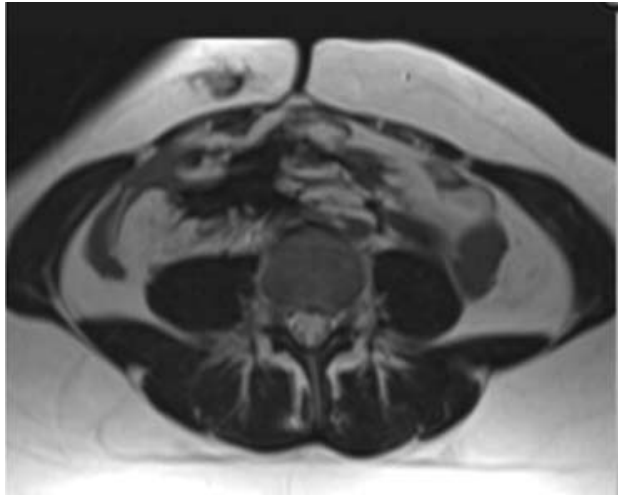

Figure 13. A low intensity T2-weighted MR image of the desmoid tumor (21)

can in some cases project into the lumen or cause a mass effect on adjacently located bowels. Small bowel leiomyomas can appear as a homogenous focal round-shaped mass that has intense, constant enhancement. The tumor also shows uniform enhancement that is greater than that of the adjacent bowels when shown on post-gadolinium images (18). On T2-weighted images, leiomyoma is displayed as hypo-intense (low signal) round and smooth mural defect that is demarcated by sharp angles to the walls of the intestine (Figure 11).

Carcinoid tumors, however, cause focal and asymmetric bowel wall thickening while manifesting as a nodular thickening of the wall. In other cases, it can manifest as a smooth sub-mucosal mass. The primary tumors display contrast enhancement and can range from 2 to $4 \mathrm{~cm}$ (20). Typically, the tumors are hypo-intense (low signal) to muscle on T2-weighted images (Figure 12). The mesentery changes in response to tryptophan and serotonin secretion. The diagnosis for carcinoid tumors involves MR imaging, serum chromogranin A levels, and 5-hydroxyindoleacetic acid (5-HIAA) urinary excretion levels.

Desmoid tumors are benign myofibroblastic neoplasms that originate from deep fibromatoses. Although they are associated with aggressive local infiltration and Gardener syndrome, the tumors do not possess metastatic potential. However, the hostile local permeation and compression of nearby structures have a high rate of relapse (10). Desmoid tumors display a low SI on T2-weighted MR images, which are often influenced by the tumor's fibrous nature (Figure 13).

Gastrointestinal lymphomas form between one and two percent of gastrointestinal malignancies. The tumors can have various gross appearances such as diffusely infiltrating tumors producing full-thickness mural thickening, polypoid tumors protruding into the lumen, as well as large, fungating, and exophytic masses that are highly prone to fistula formation and ulceration (22). The walls of the bowel can appear dilated if the tumors are diffuse infiltrating because of interfer- 
ence with the usual regulation of smooth bowel muscles. Bowel masses and dilatation that do not have proximal bowel obstruction suggest lymphoma. Lymphomatous invasion and damage of muscle layers result in aneurysmal dilatation of small-sized bowels that have lymphoma, which is caused by the loss of muscle tone where the tumor is attached to the intestinal wall. When viewed on T2-weighted images, the tumors have intermediate low SI (22).

\section{CONCLUSION}

MR imaging defines a well-developed technique that is used to examine tumors. MR imaging allows identification of tumor characteristics such as location, size, and content. In other cases, the imaging technique allows identification of the tumor's stage of development as well as whether it is benign or malignant. T2-weighted images involve presentation of basic MR imaging sequences that are determined by two key parameters of the spin echo, such as the time of repetition and the relative time taken to echo. Structures that have a short T2 relaxation time appear as hypo-intense (low signal) on T2-weighted images while those with a long time appear as hyper-intense (high signal).

Hypo-intense (low signal) tumors presented on $\mathrm{T} 2$-weighted images are generated when the $\mathrm{T} 2$ relaxation time is shortened. The shortening often transpires as a result of the effect of paramagnetic substances including blood, contrast medium, melanin, and mineral substances or the absence of excited protons such as ra- pid turbulent flows and air-containing spaces. Other causes can involve a high viscosity of protein and colloid material concentration as for protein and mucous-containing tumors or reduced extracellular concentration of fluid such as in highly cellular tumors. Identifying the location and morphology of pathological modifications that result in T2-hypointensity makes it possible to narrow the differential diagnosis. Similarly, having knowledge of such aspects enhances the possibility of making the final and correct diagnosis based solely on an MR imaging examination.
Abbreviations
MR - Magnetic resonance
SI - Signal intensity
TCCs - Transitional cell carcinomas
pRCCs - Papillary cell carcinoma
RCCs - renal cell carcinomas
cRCC - clear renal cell carcinoma
AML - Angiomyolipoma

Conflict of Interests: The authors declare that there are no conflicts of interest related to this article.

Funding: None

\section{Licensing}

This work is licensed under a Creative Commons Attribution 4.0 International (CC BY 4.0) License.

\title{
Sažetak
}

\section{TUMORI BUBREGA, KARLICE I MEZENTERIJUMASA NISKIM INTENZITETOM SIGNALA NA T2 PONDERISANOJ MR SLICI: PREGLED}

\author{
Dhulaimi Mohammad, ${ }^{1}$ Aldarmasi Moroj ${ }^{2}$ \\ ${ }^{1}$ Radiology Department, King Abdullah Medical Complex, Ministry of Health, Jeddah, Saudi Arabia \\ ${ }^{2}$ Community Medicine Department, Faculty of Medicine, King Abdulaziz University, Jeddah, Saudi Arabia
}

Magnetna rezonanca (MR) intraabdominalnih tumora je neophodna za kliničku praksu. MR omogućava optimalnu evaluaciju masa zbog svojstvenog kontrasta mekih tkiva i mogućnosti multiplanarnog skeniranja. Tumori T2 niskog signala nisu česti, i specijalisti treba da budu pažljivi prilikom njihovog interpretiranja.

Tumori koji sadrže glatke mišiće, visok nukleus-citoplazma odnos ili su papilarne građe, imaju ten-

\section{REFERENCES}

1. Ho AA, Khara SS, Ferguson DJ, Mohammed MF, Chang SD, Harris AC. A PSA for radiologists: pictorial review denciju da prikažu nizak intenzitet signala na T2 ponderisanoj slici. Kao rezultat toga, postaje esencijalno otkriti i znati razne karakteristike koje definišu svaki tumor. Identifikacija tumora i svesnost o niskom intenzitetu signala na T2 ponderisanoj slici, pomažu radiolozima da postave finalnu dijagnozu.

Ključne reči: magnetna rezonanca, dijagnoza, tumor, signal niskog intenziteta. 
in management of desmoid-type fibromatosis: a primer for radiologists. Radiographics. 2016; 36(3): 767-82.

3. Vedanayagam M, Bhattacharya B, Sriprasad S. Magnetic resonance imaging and the use in small renal masses. Indian J Surg Oncol. 2017; 8(1): 19-23.

4. Kim Y, Sung DJ, Sim KC, Han NY, Park BJ, Kim MJ, et al. Renal tumors with low signal intensities on T2-weighted MR image: radiologic-pathologic correlation. Abdom Radiol. 2017; 42(8): 2108-18.

5. Sureka B, Khera PS. Radiologic classification and imaging features of renal angiomyolipomas according to the amount of fat. AJR Am J Roentgenol. 2018; 210(3): W136.

6. Herruela-Suffee C, Warin M, Castier-Amouyel M, Dallery F, Bonnaire B, Constans JM. Whole-body MRI in generalized cystic lymphangiomatosis in the pediatric population: diagnosis, differential diagnoses, and follow-up. Skeletal radiology. 2016; 45(2): 177-85.

7. Pedrosa I, Sun MR, Spencer M, Genega EM, Olumi AF, Dewolf WC, et al. MR imaging of renal masses: correlation with findings at surgery and pathologic analysis. Radiographics. 2008; 28(4): 985-1003

8. Oliva MR, Glickman JN, Zou KH, Teo SY, Mortelé KJ, Rocha MS, et al. Renal cell carcinoma: $\mathrm{t} 1$ and $\mathrm{t} 2$ signal intensity characteristics of papillary and clear cell types correlated with pathology. AJR Am J Roentgenol. 2009; 192(6): 1524-30.

9. Lopes Vendrami C, Parada Villavicencio C, De Julio TJ, Chatterjee A, Casalino DD, Horowitz JM, et al. Differentiation of solid renal tumors with multiparametric MR imaging. Radiographics. 2017; 37(7): 2026-42.

10. Yen P, Khong K, Lamba R, Corwin MT, Gerscovich EO. Ovarian Fibromas and Fibrothecomas: Sonographic Correlation With Computed Tomography and Magnetic Resonance Imaging: A 5 Year Single Institution Experience. J Ultrasound Med. 2013; 32(1): 13-8.

11. Hedgire SS, Kudrimoti S, Oliveira IS, Nadkarni N, McDermott S, Hahn PF, et al. Extranodal lymphomas of abdomen and pelvis: imaging findings and differential diagnosis. Abdom Radiol. 2017; 42(4): 1096-112.

\section{Correspondence to/Autor za korespondenciju}

Mohammad Dhulaimi

Radiology Department, King Abdullah Medical Complex

Ministry of Health, Jeddah, Saudi Arabia.

Phone: +966591333345

Email:m_aldulaimi@hotmail.com
12. Beddy P, O’Neill AC, Yamamoto AK, Addley HC, Reinhold C, Sala E. FIGO staging system for endometrial cancer: added benefits of MR imaging. Radiographics. 2012; 32(1): 241-54.

13. Deshmukh SP, Gonsalves CF, Guglielmo FF, Mitchell DG. Role of MR imaging of uterine leiomyomas before and after embolization. Radiographics. 2012; 32(6): E251-E81.

14. Jung DC, Kim SH, Kim SH. MR imaging findings of ovarian cystadenofibroma and cystadenocarcinofibroma: clues for the differential diagnosis. Korean J Radiol. 2006; 7(3): 199-204.

15. Khashper A, Addley HC, Abourokbah N, Nougaret S, Sala E, Reinhold C. T2-hypointense adnexal lesions: an imaging algorithm. Radiographics. 2012; 32(4): 1047-64.

16. Gangadhar K, Mahajan A, Sable N, Bhargava P, editors. Magnetic resonance imaging of pelvic masses: a compartmental approach. Seminars in Ultrasound, CT and MRI; 2017: Elsevier.

17. Claus FG, Hricak H, Hattery RR. Pretreatment evaluation of prostate cancer: role of MR imaging and $1 \mathrm{H}$ MR spectroscopy. Radiographics. 2004; 24(suppl_1): S167-S80.

18. Buragina G, Magenta Biasina A, Carrafiello G. Clinical and radiological features of mesenteric panniculitis: a critical overview. Acta Biomed. 2019; 90(4): 411-22.

19. Fasih N, Prasad Shanbhogue AK, Macdonald DB, Fraser-Hill MA, Papadatos D, Kielar AZ, et al. Leiomyomas beyond the uterus: unusual locations, rare manifestations. Radiographics. 2008; 28(7): 1931-48.

20. Chung EM, Biko DM, Arzamendi AM, Meldrum JT, Stocker JT. Solid tumors of the peritoneum, omentum, and mesentery in children: radiologic-pathologic correlation: from the radiologic pathology archives. Radiographics. 2015; 35(2): 521-46.

21. Sinha A, Hansmann A, Bhandari S, Gupta A, Burling $\mathrm{D}$, Rana $\mathrm{S}$, et al. Imaging assessment of desmoid tumours in familial adenomatous polyposis: is state-of-the-art $1.5 \mathrm{~T}$ MRI better than 64-MDCT? Br J Radiol. 2012; 85(1015): e254-e61.

22. Sharma P, Yadav S, Needham CM, Feuerstadt P. Sclerosing mesenteritis: a systematic review of 192 cases. Clin J Gastroenterol. 2017; 10(2): 103-11. 